\title{
CONGENITAL OCULOMOTOR PALSY: ASSOCIATED NEUROLOGICAL AND OPHTHALMOLOGICAL FINDINGS
}

\author{
M. D. TSALOUMAS ${ }^{1}$ and H. E. WILLSHAW ${ }^{2}$ \\ Birmingham
}

\begin{abstract}
SUMMARY
Congenital fourth and sixth nerve palsies are rarely associated with other evidence of neurological abnormality, but there have been conflicting reports in the literature on the associations of congenital third nerve palsy. In order to clarify the situation we report a series of 14 consecutive cases presenting to a paediatric tertiary referral service over the last 12 years. In this series of children, 5 had associated neurological abnormalities, lending support to the view that congenital third nerve palsy is commonly a manifestation of widespread neurological damage. We also describe for the first time a phenomenon of digital lid elevation to allow fixation with the affected eye. Two children demonstrated this phenomenon and in each case the accompanying neurological defect was profound. The frequency and severity of associated deficits is analysed, and the mechanism of fixation with the affected eye is discussed.
\end{abstract}

Congenital oculomotor nerve palsy is a well-documented condition; however, the association with physical and neurological abnormalities is variously reported in the literature. In a study by Miller, ${ }^{1}$ of solitary oculomotor nerve palsies in children, 13 congenital cases had no physical or neurological abnormalities. This is in contrast to the study by Balkan and Hoyt, ${ }^{2}$ where 7 of the 10 patients had focal neurological involvement or developmental delay; and the more recent series by $\mathrm{Hamed}^{3}$ in which 10 of 14 cases had associated neurological involvement. Congenital oculomotor palsy has also been reported in association with cerebral palsy with hemiplegia contralateral to the side of the third nerve palsy, ${ }^{4}$ cerebellar hypoplasia ${ }^{5}$ and aplasia of the basal ganglia. ${ }^{6}$

From: ${ }^{1}$ Birmingham and Midland Eye Hospital; ${ }^{2}$ Birmingham Children's Hospital, Birmingham, UK.

Correspondence to: Miss M. D. Tsaloumas, 4 Hillfield Road, Solihull, West Midlands B91 3JE, UK.
In our group of patients we found a high incidence of neurological abnormalities, in some cases associated with abnormal findings on CT scanning. Aberrant regeneration, preferential fixation with the paretic eye, amblyopia of the non-involved eye and asymmetric nystagmus have all been reported as associated ophthalmic findings. ${ }^{1-3,7-9}$ However, we describe for the first time a phenomenon of digital lid elevation to allow fixation with the affected eye. Two children demonstrated this phenomenon and in each case the accompanying neurological defect was profound.

\section{PATIENTS AND METHODS}

Fourteen children ( 8 boys, 6 girls) with a diagnosis of congenital oculomotor palsy presented to our paediatric tertiary referral centre over the 12 years from 1982 to 1994. One case was bilateral; therefore details of 15 affected eyes were available for this analysis. Age at initial presentation to our unit ranged from 2 months to 8 years, but $75 \%$ of children were seen before 24 months. Follow-up ranged from 2.5 to 12 years. A detailed gestation and birth history was obtained for each child and clinic details were derived from serial clinical examinations by one of us (H.E.W.).

Ophthalmic evaluation included cycloplegic refraction, and fundus and ocular motility examination. Visual acuity was measured using acuity cards in the very young, and in the older children by Kay pictures and Cardiff acuity cards. In a number of children where individual visual acuities from each eye could not be obtained on the initial visits, the visual acuity with both eyes open (BEO) has been recorded. Final corrected visual acuities for the purposes of this study were the ones recorded on the last clinic visit before cessation of the study. They were measured with either Sheridan Gardner or Snellen tests. In addition all patients underwent detailed neurological 
Table I. Summary of clinical findings

\begin{tabular}{|c|c|c|c|c|c|c|c|c|c|}
\hline \multirow{2}{*}{$\begin{array}{l}\text { Patient } \\
\text { no. }\end{array}$} & \multirow[b]{2}{*}{ Sex } & \multirow{2}{*}{$\begin{array}{l}\text { Palsied } \\
\text { eye }\end{array}$} & \multicolumn{2}{|c|}{ Initial VA } & \multirow{2}{*}{$\begin{array}{l}\text { Pupil } \\
\text { involved }\end{array}$} & \multirow{2}{*}{$\begin{array}{l}\text { Aberrant } \\
\text { innervation }\end{array}$} & \multirow[b]{2}{*}{ Nystagmus } & \multicolumn{2}{|c|}{ Final VA } \\
\hline & & & Right & Left & & & & Right & Left \\
\hline 1 & M & Left & $6 / 18$ & $6 / 12$ & Yes & Yes & Yes & $6 / 9$ & $6 / 9$ \\
\hline 2 & M & Left & $6 / 36$ & $6 / 24$ & Yes & No & Yes & $6 / 36$ & $6 / 18$ \\
\hline 3 & $\mathrm{~F}$ & Right & $6 / 60$ & $3 / 60$ & No & Yes & Yes & $6 / 36$ & $6 / 36$ \\
\hline 4 & $\mathrm{~F}$ & Right & $\mathrm{BEO}$ & $6 / 24$ & No & No & No & $6 / 9$ & $6 / 5$ \\
\hline 5 & $\mathbf{M}$ & Left & $6 / 36$ & $4 / 60$ & Yes & No & No & $6 / 12$ & $6 / 60$ \\
\hline 7 & $\mathrm{~F}$ & Right & $\mathrm{BEO}$ & $6 / 12$ & Yes & No & No & $1 / 60$ & $6 / 6$ \\
\hline 8 & M & Right & $\mathrm{BEO}$ & $6 / 9$ & No & No & No & $6 / 9$ & $6 / 9$ \\
\hline 9 & M & Right & $\mathrm{BEO}$ & $6 / 24$ & No & No & No & $6 / 60$ & $6 / 12$ \\
\hline 10 & $\mathbf{M}$ & Left & $\mathrm{BEO}$ & $6 / 24$ & Yes & No & No & $6 / 5$ & $6 / 36$ \\
\hline 11 & M & Right & $1 / 60$ & $6 / 6$ & Yes & Yes & No & $6 / 60$ & $6 / 5$ \\
\hline 12 & $\mathrm{~F}$ & Bilateral & $6 / 12$ & $6 / 12$ & $\mathrm{R}$ yes, $\mathrm{L}$ no & L yes & No & $6 / 12$ & $6 / 12$ \\
\hline 13 & $\mathbf{M}$ & Left & $6 / 36$ & $1 / 60$ & No & No & No & $6 / 6$ & $6 / 12$ \\
\hline 14 & $\mathrm{~F}$ & Right & $6 / 9$ & $6 / 36$ & Yes & Yes & Yes & $6 / 12$ & $6 / 5$ \\
\hline
\end{tabular}

VA, visual acuity; BEO, both eyes open.

assessment by a paediatric neurologist and 10 of the 14 had neuroradiological imaging.

\section{RESULTS}

Patient details are shown in Tables I and II. Initial visual acuities are, for comparison purposes, recorded as Snellen equivalents in Table I.

Of the 14 children, 5 had specific neurological abnormalities. These included 2 children with cerebral palsy and spastic tetraplegia, 1 child with left hemiplegia, 1 with hypotonia and left torticollis and 1 child with severe psychomotor retardation and epilepsy. A further 3 children had non-specific neurological features including behavioural disturbance, developmental delay and seizures.

CT scanning was abnormal in 5 of the 10 examinations, but there was no one consistent abnormality. Findings included brain stem infarction, cerebellar infarction, a Chiari type 1 malformation, an intraconal haemangioma, and a midline, midbrain lesion. In the child with a right intraconal haemangioma, a right third nerve palsy (with no proptosis or abducens involvement) was associated with a left hemiplegia. These features are characteristic of Weber's syndrome and it was, therefore, assumed that the haemangioma was an incidental finding and not causally related to the oculomotor palsy.

Three of the 5 children with focal neurological abnormalities had abnormal CT scans, including patient 12 who had bilateral oculomotor palsy with severe psychomotor delay and a high, midline, midbrain lesion on imaging.

Three patients were born at less than 38 weeks gestation and suffered birth hypoxia. Two other patients had documented traumatic amniocentesis.

The visual acuity was initially better in the involved paretic eye in 4 cases and 2 of these demonstrated the phenomenon of digital lid elevation to allow fixation with the affected eye. The two children who were digitally elevating the ptotic lid (patients 2 and 3 ) were premature (born at 30 weeks and 36 weeks gestation respectively) and had notable neurological problems.

Nystagmoid movements were observed in 4 children. In 2 this was a true bilateral nystagmus. In the other 2 children, nystagmoid movements were observed in the non-paretic eye. These were the same 2 children who demonstrated the oculo-digital manoeuvre, manually elevating the ptotic lid to allow fixation with the paretic eye which showed no

Table II. Other findings

\begin{tabular}{rlll}
\hline Patient no. & Birth problems & Imaging findings & Neurological findings \\
\hline 1 & No & Negative & No \\
2 & Premature, low birth weight & Negative & Cerebral palsy, tetraplegia, hypotonia \\
3 & Premature, birth asphyxia & R brain stem infarct & Torticollis, developmental delay \\
4 & No & R intraconal haemangioma & Left hemiplegia \\
5 & No & Negative & Developmental delay \\
6 & Traumatic amnio $\times 3$ & R cerebellar infarct & Cerebral palsy, left spasticity \\
7 & No & Chiari l malformation & Behavioural problems \\
8 & No & No scan & No \\
9 & No & No scan & No \\
10 & No & Negative & No \\
11 & No & No scan & No \\
12 & Traumatic amnio $\times 1$ & Midline midbrain lesion & No \\
13 & No & Negative & Severe psychomotor delay, seizures \\
14 & Birth hypoxia, premature, & No scan & No \\
& cephalohaematoma & & No \\
\hline
\end{tabular}




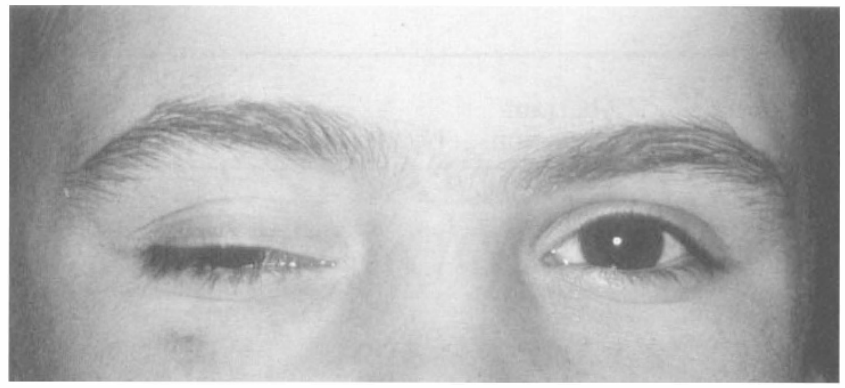

Fig. 1. Patient 11 in the primary position of gaze.

nystagmoid movements and had the better visual acuity. The 4 patients with better visual acuity in the affected eye and preferred fixation with this eye also adopted an abnormal head posture with a face turn to the non-affected side. This particular head posture was also adopted by patient 8 who had equal visual acuities and fixated with either eye.

Pupil involvement was present in 8 eyes and consisted of 4 eyes in which the affected pupil was larger than in the fellow eye and 4 eyes where the pupil was miotic in comparison with the normal eye.

In 14 of the 15 eyes ptosis was present, 1 patient having partial third nerve involvement with pupil and lid sparing. Ptosis was characterised as complete in 6 eyes, moderate in 7 eyes (covering visual axis) and minimal (visual axis clear) in 1 eye. Evidence of aberrant innervation was found in 5 eyes. Two eyes exhibited miosis on attempted adduction. Lid retraction on downgaze was observed in 2 eyes (Figs. 1,2), and 1 eye had a Marcus Gunn jaw-winking phenomenon. A further 3 eyes also demonstrated lid retraction on taking up fixation with the paretic eye, but whether this is true misdirection or occurs as a result of increased innervation to the palsied superior rectus/levator complex is controversial.

In the child with bilateral but asymmetric third nerve palsies there was pupil sparing but a complete ptosis on the right, while on the left there was a fixed dilated pupil with moderate ptosis and aberrant regeneration characterised by the Marcus Gunn jawwinking phenomenon. Scanning in this patient showed a midline lesion in the midbrain, appear-

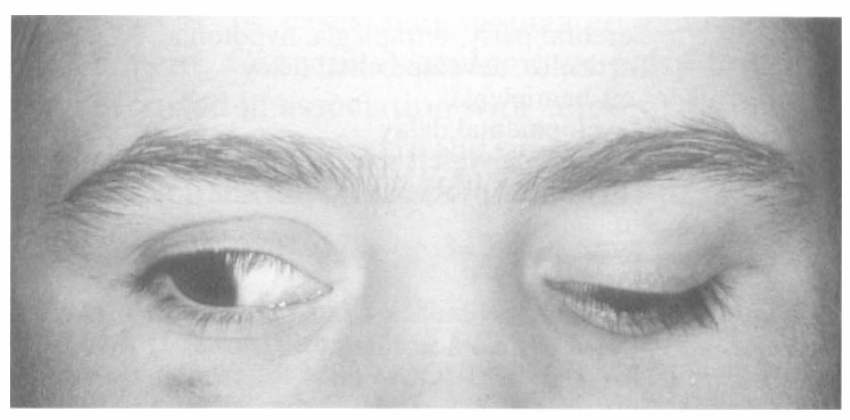

Fig. 2. Patient 11 demonstrating lid retraction on downgaze. ances consistent with a cavity with surrounding gliosis.

\section{DISCUSSION}

This study supports the work of recent authors (in contrast to earlier studies) in establishing that congenital oculomotor palsy is often associated with diverse and sometimes profound neurological abnormalities. In the series by Hamed, ${ }^{3} 10$ of 14 patients had associated neurological abnormalities, and Balkan and Hoyt ${ }^{2}$ reported 10 patients of whom 7 exhibited neurological deficit. In our series, over $50 \%$ of the patients studied had neurological problems, emphasising that the condition is neither benign nor solitary as has been suggested by earlier authors. ${ }^{1,8}$ The diversity of the associated neurological findings suggests that both the site and type of the lesion responsible for the congenital oculomotor palsy are variable, as well as the timing of its occurrence. Some cases may be attributable to events during intrauterine life, while in others documented perinatal trauma has been implicated. ${ }^{3,9}$ The high incidence of associated neurological abnormalities found in this and other series suggests a possible role for intrauterine brain stem injury.

In our series, 3 children were premature and suffered birth hypoxia. Two of these had neurological abnormalities while the third child, who had no neurological abnormalities initially, despite a traumatic delivery with cephalohaematoma, later developed focal seizures during the review period. Of the 2 children with neurological abnormalities 1 had a brain stem infarct on imaging with generalised developmental delay while the other, despite a normal CT scan, had cerebral palsy and spastic tetraplegia, both of these indicating widespread central damage.

Bilateral congenital oculomotor palsies, although rare, have been reported in the literature ${ }^{6,10}$ and probably indicate a true nuclear lesion. The one child in our series with bilateral palsies had unilateral pupil involvement (right) and unilateral aberrant innervation (left). MRI showed a midline, midbrain lesion, which could possibly account for a bilateral oculomotor palsy. It is interesting to note that this patient had a traumatic amniocentesis at 16 weeks and neurological problems associated with traumatic amniocentesis in the second trimester have previously been reported. ${ }^{11}$

Aberrant regeneration is well documented in acquired oculomotor palsy, most commonly following aneurysms or trauma in adults and trauma in children. It also appears to be common in congenital cases. ${ }^{1-3,9}$ In congenital oculomotor palsy various patterns of misdirection have been observed including pupillary miosis with adduction and synkinetic lid movements. ${ }^{1,3,9}$ Several authors have challenged the 
concept that misdirected axons following peripheral nerve injury lead to the features of aberrant regeneration. They suggest that central mechanisms may be involved, particularly central synaptic reorganisation. ${ }^{2,12}$

Although pupil involvement in congenital oculomotor palsy seems to be the rule, pupil sparing does not necessarily preclude a central lesion. Good ${ }^{6}$ has postulated that an early embryological event could selectively damage both the oculomotor nerve nuclei and basal ganglia structures while partially sparing the Edinger-Westphal nucleus.

Five eyes in our series exhibited synkinetic movements. Eyelid retraction on downgaze (2 eyes), miosis on attempted adduction (2 eyes) and the Marcus Gunn jaw-winking phenomenon (1 eye) are recognised instances of misdirection. However, a further 3 eyes demonstrated eyelid retraction on taking up fixation with the paretic eye. This may be associated with the attempted adduction movement that fixation would involve, as described by Walsh, ${ }^{13}$ but may also be a consequence of attempted elevation when fixing with the hypotropic paretic eye, and therefore increased innervation to the palsied superior rectus/levator complex.

Preferential fixation with the paretic eye has been reported before by Keith ${ }^{14}$ and Hamed. As described by these authors the paretic eye may have a fixational advantage as the coexisting nystagmus they observed was damped when fixing with the paretic eye. In 4 of our cases not only did the patient prefer to fixate with the paretic eye but 2 (patients 1 and 14) continued to do so even after amblyopia treatment to the other eye improved the visual acuity to the level of the paretic eye. The other 2 patients (2 and 3) demonstrated the unusual manoeuvre of digital lid elevation to allow fixation with the paretic eye, the other eye remaining amblyopic. To our knowledge this is the first time this phenomenon has been described.

The explanation of this fixation preference is difficult. It may be, as suggested by Keith, ${ }^{14}$ that it relates to ocular dominance. However, we feel it may be that the lesion causing the oculomotor palsy has also caused the nystagmus. The lack of mobility of the affected eye would then give it an advantage (in terms of maintaining steady foveal fixation) over its more mobile partner, as suggested by Hamed. ${ }^{3}$

\section{CONCLUSION}

Any child presenting with a congenital oculomotor palsy should be examined neurologically to ensure there is no focal or generalised associated pathology. Appropriate management of the ocular problems will require consideration of preferential fixation with the paretic eye, amblyopia of the non-paretic eye and the possibility of aberrant regeneration.

Key words: Congenital oculomotor palsy, Nystagmus, Aberrant innervation, Neurological abnormalities.

\section{REFERENCES}

1. Miller NR. Solitary oculomotor nerve palsy in childhood. Am J Ophthalmol 1977;83:106-11.

2. Balkan R, Hoyt CS. Associated neurologic abnormalities in congenital third nerve palsies. Am J Ophthalmol 1984;97:315-9.

3. Hamed LM. Associated neurologic and ophthalmic findings in congenital oculomotor nerve palsy. Ophthalmology 1991;98:708-14.

4. Ing EB, Sullivan TJ, Clarke MP, Buncic JR. Oculomotor nerve palsies in children. J Pediatr Ophthalmol Strabismus 1992;29:331-6.

5. White L, Mumma JV, Tomasovic JJ. Congenital oculomotor nerve palsy, cerebellar hypoplasia, and facial capillary haemangioma. Am J Ophthalmol 1992;113:497-500.

6. Good WV, Barkovich AJ, Nickel BL, Hoyt CS. Bilateral congenital oculomotor nerve palsy in a child with brain anomalies. Am J Ophthalmol 1991;111: 555-8.

7. Kazarin EL, Flynn JT. Congenital third nerve palsy with amblyopia of the contralateral eye. J Pediatr Ophthalmol Strabismus 1978;15:366-7.

8. Victor DI. The diagnosis of congenital unilateral third nerve palsy. Brain 1976;99:711-8.

9. Harley RD. Paralytic strabismus in children: etiologic incidence and management of third, fourth, and sixth nerve palsies. Ophthalmology 1980;87:24-43.

10. Flanders M, Watters G, Draper J, O'Gorman A. Bilateral congenital third cranial nerve palsy. Can J Ophthalmol 1989;24:28-30.

11. Naylor G, Roper JP, Willshaw HE. Ophthalmic complications of amniocentesis. Eye 1990;4:845-9.

12. Lepore FE, Glaser JS. A critical appraisal of acquired oculomotor nerve synkinesis. Arch Ophthalmol 1980;98:2206-9.

13. Walsh FB. Communications. Third nerve regeneration. Br J Ophthalmol 1957;41:577-98.

14. Keith CG. Congenital ocular palsy. Br J Ophthalmol 1972;56:356-61. 